\title{
Building an endobariatric program: lessons learned
}

\section{(이요 $\odot$}

\section{Authors}

Dilhana Badurdeen ${ }^{1}$, Abdellah Hedjoudje ${ }^{1,2}$, Mohamad Itani ${ }^{1}$, Lea Fayad ${ }^{1}$, Jad Farha ${ }^{1}$, Margo Dunlap ${ }^{1}$, Lawrence Cheskin $^{3}$, Michael Schweitzer ${ }^{4}$, Kristen Koller ${ }^{1}$, Christian Hartman ${ }^{1}$, Andreas Oberbach ${ }^{1}$, Mouen A. Kashab ${ }^{1}$, Anthony Kalloo' ${ }^{1}$ Vivek Kumbhari ${ }^{1}$

Institutions

1 Johns Hopkins Medical Institutions - Division of Gastroenterology and Hepatology, Baltimore, Maryland, United States

2 Hôpital Beaujon - Département d'endoscopie digestive, Clichy, France

3 Johns Hopkins University Bloomberg School of Public Health - Weight Management Center, Baltimore, Maryland, United States

4 Johns Hopkins Medicine - Department of Surgery, Baltimore, Maryland, United States

submitted 28.2.2020

accepted after revision 22.5.2020

Bibliography

DOI https://doi.org/10.1055/a-1198-4598 |

Endoscopy International Open 2020; 08: E1185-E1193

(c) Georg Thieme Verlag KG Stuttgart · New York

elSSN 2196-9736

Corresponding author

Vivek Kumbhari, Johns Hopkins Hospital - Gastroenterology and Hepatology, 1800 Orleans St Sheikh Zayed Tower, Baltimore Maryland 21287, United States

Fax: +1-410-955-5000

vkumbhari@gmail.com

\section{ABSTRACT}

The emphasis on treating obesity has never been more critical, yet the complexity of delivering care has become more intricate due to new procedures, variable insurance coverage, and inconsistent reimbursement. This is our experience building an endobariatric program and treating overweight and obese patients with endobariatric therapies (EBTs) over 3 years. The primary intention of this manuscript was to educate the reader on how to build an endobariatric program, identify barriers, and provide succinct solutions to establish a successful program. The secondary aim was weight loss outcomes of procedures offered at our institution. We compiled a list of lessons learned, based on the difficulties we experienced to make it easy for others embarking on this journey. Herein, we present a business development strategy to overcome impediments, whilst offering high quality service.

The high cost and lack of insurance coverage are significant barriers. Marketing can be costly and is often a factor that is ignored particularly early on, when finances are limited. However, it is an integral component of growing the program. The percentage total body weight loss (\%TBWL) at 6 and 12 months post ESG was $17.8 \pm 6.48$ and $20.6 \pm 8.3$ $(P<0.001)$, respectively. The \%TBWL at 6 months post IGB was $14.9 \pm 9.8$ for the Orbera IGB and $12.6 \pm 7.4$ for the Reshape IGB. There was a trend of preference for ESG compared to IGB placement over the 3 years.

The key to building a successful endobariatric program is a motivated physician leader, collaborative bariatric surgeons, institutional support, and marketing. Insurance coverage will likely occur in the near future and programs must be prepared to manage the massive influx of patients that will likely request these procedures.

\section{Introduction}

Obesity has reached epidemic proportions, yet thus far, no country has succeeded in reversing its obesity epidemic [1]. The Centers for Disease Control and Prevention (CDC) estimates that in the United States, the prevalence of obesity defined as a body mass index (BMI) greater than $30 \mathrm{~kg} / \mathrm{m}^{2}$ is approximately $42.4 \%$ [2], which translates to a staggering
93.3 million US adults [3]. Obesity increases incidence of Type 2 diabetes mellitus (DM2), dyslipidemia, hypertension (HTN), cardiovascular and non-alcoholic fatty liver disease (NAFLD) as well as all-cause mortality [1]. The American Gastroenterological Association (AGA) has embraced obesity as a chronic relapsing disease and supports a multidisciplinary management approach that includes an intensive weight loss intervention to facilitate improved outcomes and patient experience [4]. 
There has been an exponential evolution of new devices and procedures to treat obesity with endoscopic bariatric therapy (EBT) emerging as an innovative alternative for obese patients who have failed intense diet, lifestyle modification and pharmacotherapy, yet are reluctant to undergo bariatric surgery. EBT includes devices or instruments that require flexible endoscopy, such as intra-gastric balloons (IGB), endoscopic sleeve gastroplasty (ESG), aspiration therapy and intra-gastric Botox injection. EBT produces greater weight loss than intense diet and lifestyle therapy (IDLT) [5] and medications [6] alone. In a multicenter, randomized clinical trial (RCT) of 255 adults that had the Orbera IGB inserted, percent total body weight loss (\% TBWL) was $10.2 \%$ at 6 months compared to $3.3 \%$ in the lifestyle arm [7]. A meta-analysis of 17 studies demonstrated similar results with \%TBWL $11.2 \%$ and percent excess weight loss (\%EWL) $25.44 \%$ at 12 months [8]. A recent meta-analysis of 1772 patients that underwent ESG demonstrated \%TBWL of $15.1 \%$ at 6 months and $16.5 \%$ at 12 months [9]. In a multicenter RCT of Aspiration therapy, patients achieved \%TBWL of $14.2 \%$ at 12 months and $15.3 \%$ at 24 months [10]. Although weight loss and metabolic outcomes following EBT therapy are inferior to bariatric surgery, EBT is an acceptable alternative for patients who do not qualify or are resistant to bariatric surgery, as it is less invasive and the risk of complications appear lower [11].

The need for an intense weight loss intervention offers numerous procedural opportunities in the era of rapid and evolving endoscopic bariatric techniques; however, this is tempered by the challenges associated with knowledge acquisition, skills development, strategic planning, and program evolution. Knowledge of the disease process and relevant medications are only two of the necessary elements required for creating an EBT program. The decision to form an EBT program should involve a deeper understanding of market forces and financial resources. Due to their expertise in digestive and nutritional diseases, Gastroenterologists are uniquely qualified to lead an EBT program however, have little formal training in establishing and developing a program.

The ultimate goal is to form a multidisciplinary weight loss team comprising a bariatric endoscopist, obesity medicine physician, bariatric surgeon, registered dietitian, behavioral psychologist and exercise physiologist. In this manuscript we discuss barriers we encountered, propose pragmatic solutions and elucidate effective resources to facilitate in filling the voids in clinical knowledge and technical skills that are vital to a financially viable, and effective program.

\section{Patient acquisition and workflow}

Patients connected with our service using a designated phone number or email, the details of which were available on our program's website [12]. Patients were offered a no-cost one-onone visit with the physician and nurse coordinator at their preferred location. We followed the structure of the Practice Guide on Obesity and Weight Management, Education and Resources (POWER) guidelines [4] and began with a structured motivational approach. A weight loss intervention was then determined.
Patients with a BMI $\geq 27 \mathrm{~kg} / \mathrm{m}^{2}$, failure of weight loss through lifestyle and dietary modification, and demonstration of adequate understanding of the procedure's benefits and risks were eligible for an endoscopic bariatric intervention. Alternatives such as bariatric surgery and high-intensity diet and lifestyle therapy (HIDLT) were also discussed. HIDLT consists of a low-calorie high-protein diet, biweekly followed by monthly behavioral, nutritional, and exercise counseling, and optional resources including psychotherapy, support groups and meal replacement [5]. There is a need to shift from simplistic metrics such as BMI to complications-centric decision-making. We individualized goals of therapy to our patient's weight loss target and/or improvement in specific obesity related complications. Ethnic-specific lower BMI cutoffs have been recommended (18.5 to $22.9 \mathrm{~kg} / \mathrm{m}^{2}$ is normal range, 23 to $24.9 \mathrm{~kg} / \mathrm{m}^{2}$ overweight, and $\geq 25 \mathrm{~kg} / \mathrm{m}^{2}$ obesity for Asians), along with assessment for adiposity-related complications. Thus, we felt comfortable offering EBT to patients with a BMI of $27-30 \mathrm{~kg} / \mathrm{m}^{2}$ that we felt would benefit from an intense weight loss intervention. Patients with a $\mathrm{BMI} \geq 40 \mathrm{~kg} / \mathrm{m}^{2}$ particularly those with $\mathrm{DM} 2$, prediabetes and insulin resistance were encouraged to attend a bariatric surgery seminar or schedule an appointment with the bariatric surgeon. The contact information of patients interested in the program was forwarded to the bariatric surgery coordinator, and the others were provided with a pamphlet with the surgeons contact details. The majority of our patients did not want to proceed with surgery due to the perceived complications and fear of undergoing bariatric surgery [13] and thus requested a less invasive option for weight management. We did not deny EBT to any patient that we believed would benefit as long as the patient was aware of the outcomes and refused to undergo surgery. We believe this was an ethical approach, in the best interest of our patients and have an excellent relationship with our bariatric surgeons because of this approach. We strongly recommend that others who want to build an endobariatric program follow a similar approach. The final decision regarding bariatric surgery versus EBT was made by the patient. - Fig. 1 depicts patient flow through the program.

A pre-procedure medical weight management program does not result in superior weight loss or improve long-term weight loss outcomes following bariatric surgery. [12, 14, 15] As such, we did not offer a pre-EBT medical weight management program. We combined procedures with a 12-month follow-up program with an obesity medicine specialist, registered dietician and exercise physiologist. Patients were prescribed a low-calorie, low-carbohydrate Mediterranean diet. We recommended a physical activity goal of 10,000 steps or more per day and moderate cardiovascular exercise of 150 minutes or more per week. Recent data suggest that an intensive weight loss intervention is paramount, followed by a maintenance phase that allows patients to change their relationship with food and exercise, and embrace a sustainable 'lifestyle' that promotes a healthy weight $[4,5,16]$. Patients were prescribed weight loss medications after 12 months for weight recidivism and to augment weight loss if a plateau was reached. 
Patients found us through the program website, referring provider and screen savers throughout the hospital

\section{$\checkmark$ \\ Patients contacted the coordinator via a phone call or email \\ No cost visit with physician and program coordinator \\ Patient informs program coordinator if they decide to proceed \\ Payment is processed by financial coordinator \\ Procedure is scheduled by scheduler \\ Post procedure follow up - Behavioral psychologist, nutritionist, obesity medicine specialist, exercise physiologist}

Fig. 1 Algorithm showing patient flow through the program.

\section{What we offered}

The benefits, risks, estimated weight loss, and post-procedure follow up of ESG, IGBs, Aspiration therapy and intra-gastric Botox injection were explained at the initial visit. Exclusion criteria included active peptic ulcer disease, bleeding disorders, diagnosed eating disorders, Los Angeles (LA) Grade B or greater erosive esophagitis, and presence of a hiatal hernia greater than $2 \mathrm{~cm}$. If the patient decided to proceed with EBT, payment was processed and the procedure was scheduled. The pre- and post-procedure instructions and follow up for all procedures were identical, which streamlined the process.

ESG was performed as described by Hill et al. and Sartoretto et al. $[17,18]$ under general anesthesia (GA) with carbon dioxide $\left(\mathrm{CO}_{2}\right)$ insufflation. Technical highlights and salient features of the ESG can be found in previous publications. Patients were offered the option of a single fluid filled IGB versus a dual-balloon at the same cost. Intra-gastric Botox injection, Aspire Assist and IGB placement was performed at an out-patient ambulatory surgery center (ASC) under moderate anesthesia care (MAC) with $\mathrm{CO} 2$ insufflation. Removal was scheduled at the same ASC, but with intubation for airway protection.

\section{Outcomes assessment}

The patient database consists of all patients that had EBT at the comprehensive weight loss center. At baseline, patient height was recorded using a wall-mounted stadiometer and weight was measured using a calibrated scale with the patient wearing indoor clothing and no shoes. Patient age, sex, history of obesi- ty-related chronic medical diseases, and prior bariatric procedures were documented.

The primary outcome was to identify barriers to establishing and offering EBT. The secondary outcome was weight loss at 1 , 3, 6 and 12 months of follow-up. Adverse events (AEs) and complications were recorded up to 30 days post-procedure. The statistical analyses included subjects that reached the followup time points.

- Table 1 depicts lessons learned from our experience building an EBT program. > Table 2 depicts baseline characteristics of patients that underwent procedures. There was a trend for preference of ESG over IGB over the 3 years ( $\mathbf{F i g . 2}$ ). Patients opted for IGB placement early on, as ESG was a relatively new procedure. However, we saw a decline in the number of IGBs placed when the U.S. Food and Drug Administration (FDA) first communicated on the potential risks of hyperinflation and acute pancreatitis in February 2017. We saw a further decline after the FDA provided updates about the potential risk of death. Concurrently, we saw an increase in the number of patients opting for ESG as the long-term safety and weight loss data became available. We did not expect the substantially higher early IGB removal rate in United States. As early data on removal for intractable reflux and regurgitation became available, we started informing patients with severe gastroesophageal reflux disease (GERD). Patients were also concerned about the weight regain following IGB removal. Patients that chose ESG, often did so due to the superior long-term weight loss and tolerability based on their personal weight loss target. - Table 3 depicts the price per procedure at an ASC versus the hospital. $>$ Table 4, $>$ Table 5 , and $>$ Table 6 depicts the \%TBWL at $1,3,6$, and 12 months post-EBT. Detailed weight loss outcomes are provided in the supplementary section.

\section{Lessons learned}

The key players are a bariatric endoscopist, obesity medicine specialist, dietician, behavioral psychologist, registered nurse, and clinical and financial coordinator. In an academic institution, stakeholders will include the department and divisional leadership, anesthesia providers and ASC. In a private practice, this is likely simpler if the clinic, ASC and anesthesia are owned and operated by the physician. We believe it is fundamental to have a program that encompasses primary weight loss, weight maintenance, and treatment of weight recidivism. The gastroenterologist should lead the program, but it is worthwhile to have a formal collaboration with a bariatric surgeon. Surgeons are valuable when managing adverse outcomes from EBT; however, the bariatric endoscopist also provides value to the surgeon. Patients that meet criteria for bariatric surgery referred from an EBT program are often more open to undergoing bariatric surgery. More importantly, bariatric endoscopy has revolutionized the management of post-bariatric surgery complications such as leaks, stenosis and bleeding as surgeons have little to offer aside from revisional surgery that is seldom well received by patients [19]. Bariatric endoscopists are also able to manage post-bariatric surgery weight regain, abdominal pain, and gastroesophageal reflux disease. We recommend winning over 
- Table 1 Lessons learned.

Approval -

Ensure that you have institutional, hospital, and division chief support

Applying for institutional review board (IRB) approval prior to launching the program can cause delays, and may create hurdles.

Aspiration therapy and IGB - Do not require an institutional IRB.

ESG - Requires an IRB or an IRB exemption in an American society of metabolic and bariatric surgery (ASMBS) accredited center or center of excellence.

Key Players -

Bariatric endoscopist, registered nurse, bariatric surgeon, clinical and financial coordinator.

Other Team members - Obesity medicine specialist, registered dietician, behavioral psychologist - These services can be outsourced to a third party.

Knowledge acquisition -

Board Certification - American Board of Obesity Medicine (ABOM) - Lends credibility to the treating practitioner

Training ancillary staff, nurses and technicians - Instruction and education through industry or gastrointestinal and surgical societies

Skills development to perform EBT -

Industry led training sessions

Society led training courses - The American Society for Gastrointestinal Endoscopy (ASGE), International Federation for the Surgery of Obesity and Metabolic Disorders (IFSO), and Society of American Gastrointestinal and Endoscopic Surgeons (SAGES)

Academic center training courses - The Johns Hopkins International Therapeutic Endoscopy Course (HITEC), The Flexible Endoscopic Surgery and Bariatric Endoscopy conference (FES), Bariatric Endoscopy Sao Paulo (BESP)

Non-course related training sessions by experts

Win over the bariatric surgeon -

Provide reassurance that endobariatric procedures are simply an alternative and not a replacement to bariatric surgery

Refer patients with a $B M I \geq 40 \mathrm{~kg} / \mathrm{m}^{2}$

Include them in research publications or protocols

Invite them to speak at divisional meetings and conferences

Manage post-bariatric surgery complications. Eg: Leaks, stenosis

Manage post-bariatric surgery weight regain

Indications for EBT -

ESG, IGB and Intra-gastric Botox - BMI $\geq 30 \mathrm{~kg} / \mathrm{m}^{2}$ (lower BMIs should be considered; we offered EBT to patients with a BMI $\geq 27 \mathrm{~kg} / \mathrm{m}^{2}$ )

Aspiration therapy - BMI $35-55 \mathrm{~kg} / \mathrm{m}^{2}$

Off-label use of the device - Bridge to bariatric surgery in morbidly obese patients and prior to orthopedic surgery - Benefit and added risk must be communicated and documented

Financial connotations -

Understand market forces and financial resources

Negotiate with more than one ASC

Negotiate with a hospital-based endoscopy unit for patients with a higher BMI or a precarious airway

Sharing of payment between the hospital, division, endoscopist and anesthesia team must be discussed

Utilization of a third party for follow up visits can expedite the development of a program in a cost-conscious manner

Initial consultation -

No-cost one-on-one visit with the physician

Roll into cost of procedure

Follow-up Care -

Can be outsourced to a third-party medical weight loss center to reduce initial start-up costs

Working with several programs in different geographical locations will make follow-up easy for patients as they can choose the most convenient location

Excellent source of referrals

Strategic planning -

Provide patient with written information regarding procedure

Provide patient with Pre and post procedure instructions 2 weeks prior to the procedure

Provide client with a patient contract that must be signed before payment is processed

Ensure that consent is signed prior to the scheduled procedure

Billing and coding -

Lack of terminology for new procedures can cause confusion

Create a dummy code for the no cost initial clinic consultation and individual EBT's

Educate financial and coding team regarding dummy codes and modifiers that will be used to prevent inadvertent billing of patients' insurance

Cost of the procedure -

Cost will decrease over time as endoscopist becomes more experienced. Be prepared to re-negotiate pricing

Consider being a part of clinical trials. Patients may qualify for a procedure even if they cannot afford it

Patients with no benefits for bariatric surgery often prefer a less invasive intervention such as ESG or IGB

A flexible payment plan will make the program more accessible 
Insurance coverage -

For EBT will likely occur in the near future

Hospital admission, or surgical intervention if a complication occurs - will be billed to patients' insurance, and may or may not be covered

Marketing -

Consider creating a website with a three-dimensional experience of your clinic, procedure suite, follow up and patients proposed weight loss journey Take one cards

Education of primary care physicians

Consider interviews on local radio shows

Have a digital footprint by being active on social media platforms such as Facebook and Instagram

Hospital flat screen advertising

Internet search engine optimization

Professional YouTube videos

Word of mouth

Offer employees a discount

Clinical trials

Program evolution

Managing emergent complications or removal of an IGB due to intolerance can be difficult if you are the only provider. Consider cross-training a colleague or developing a working relationship with a practice nearby

Maintaining a database -

Track weight loss data - Allows one to monitor the success of program

Quality assurance for every component of the program including dietician, behavioral psychologist and exercise physiologist should be in place

Consider joining a registry such as an endoscopic suturing registry or endoscopic bariatric therapy registry to track outcomes, adverse events and compare data

Table 2 Baseline characteristics.

\begin{tabular}{|c|c|c|c|}
\hline Baseline characteristic & ESG $(n=108)$ & Orbera $(n=34)$ & Reshape $(\mathrm{n}=33$ ) \\
\hline Age, years & $47.50(11.93)$ & $48.24(11.22)$ & 1 \\
\hline Sex, female (\%) & $78(71.7)$ & $33(97.1)$ & 1 \\
\hline Height, meters & $1.69(0.09)$ & $1.63(0.06)$ & $1.66(0.08)$ \\
\hline Baseline weight, kg & $113.77(28.66)$ & $93.86(23.21)$ & $100.56(20.31)$ \\
\hline Baseline BMI, kg/m² & $40.40(7.88)$ & $34.17(7.01)$ & $36.34(5.15)$ \\
\hline Diabetes mellitus (\%) & $7(6.5)$ & $2(5.9)$ & 1 \\
\hline Hypertension (\%) & $17(15.9)$ & $9(26.5)$ & 1 \\
\hline GERD (\%) & $7(6.5)$ & $4(11.8)$ & 1 \\
\hline Obstructive sleep apnea (\%) & $17(15.9)$ & 1 & 1 \\
\hline
\end{tabular}

the bariatric surgeon by referring patients that qualify for surgery, including them in research publications and inviting them to speak at conferences. It is important to avoid exaggerating outcomes and to quote literature when debating. You should inform them of training sessions you attend so you may grow knowledge together, while providing constant reassurance that EBT is simply an alternative and not a replacement of bariatric surgery. It is seldom that a bariatric surgeon will perceive an EBT program as a threat, as less than $2 \%$ of patients that qualify for bariatric surgery actually undergo the procedure. In rare instances when a bariatric surgeon cannot be won over, ensure that you have the support of your division chief and hospital before proceeding.

Obesity medicine specialists are often board-certified in Obesity Medicine through the American Board of Obesity Medicine (ABOM) [20]. Board certifications may lend credibility to the treating practitioner, but are a point of contention among providers who are wary of excessive regulation, additional examination fees, and annual dues. They are a useful addition to the program, as we all know weight recidivism after any weight loss intervention is perplexing.

We outsourced follow-up to a third-party weight loss center within our institute. This reduced the burden of hiring additional personnel, before the program was established and making a profit. Multiple such programs are well established and willing to collaborate for competitive cash pay rates. Working with several programs in different geographical locations will allow patients to follow at the most convenient location. In addition, it is an excellent source of referrals.

We offered an initial no-cost consultation at a clinic in the hospital, to motivate patients to learn about our center. This may encourage patients that are "shopping" for a provider. In 


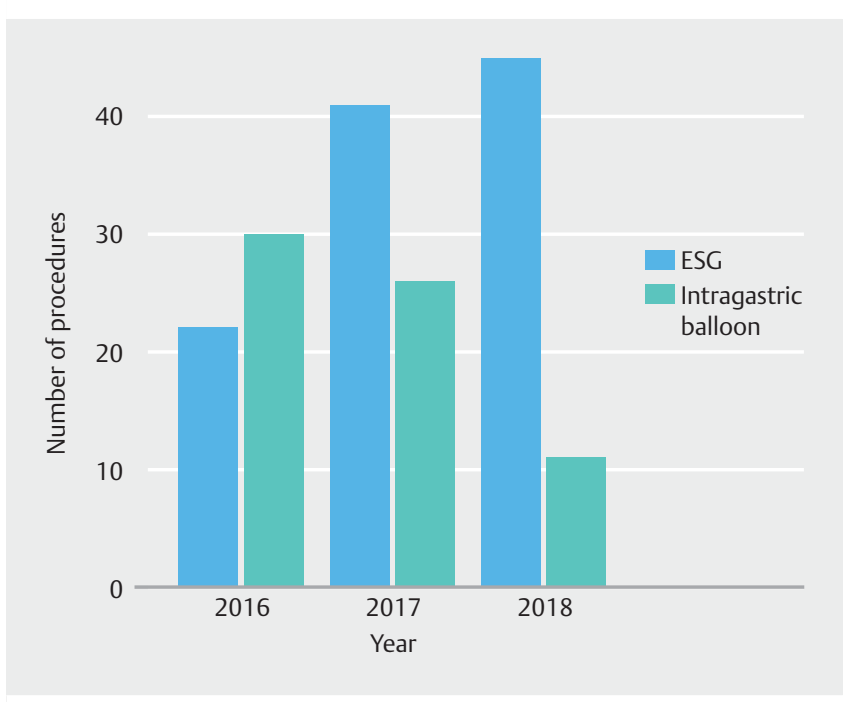

Fig. 2 Bar chart of procedures performed over 3 years.

- Table 3 Price per procedure at Ambulatory Surgery Center (ASC) versus hospital.

\begin{tabular}{|l|l|l|}
\hline Procedure & ASC & Hospital \\
\hline Endoscopic sleeve gastroplasty & $\$ 12,265$ & $\$ 15,000$ \\
\hline Intra-gastric balloon & $\$ 7000$ & $\$ 12,000$ \\
\hline Aspire assist & $\$ 7000$ & $\$ 16,500$ \\
\hline Intra gastric Botox & $\$ 9,000$ & $\$ 12,440$ \\
\hline
\end{tabular}

order to ensure that we were not burdened with clients that were not interested, patients were educated prior to their scheduled visit. We emailed patients a program packet containing information about all our procedures, weight loss outcomes, a link to our website and information on cost. It was made clear to patients that EBTs are cash pay procedures with no exception. To be fair to the physician, work relative value units (wRVUs) were provided for this visit.

We offered an assortment of devices to enhance referrals through company portals, which reduces the cost of marketing. At least $50 \%$ of our patients arrived with preconceived notions and were surprised to hear the benefits, risks, similarities, and differences between procedures. Subsequent to their visit, a significant percentage of clients opted to have a different procedure based on the initial discussion. Patient acceptance of Aspiration therapy has been slow. Intra-gastric Botox injection for weight loss is an off-label use of Botox. It is expensive, and the effect is short-lived, however, patients continue to inquire about it, as they feel it is the least invasive option. We incorporated these procedures into our practice to be comprehensive, but in retrospect, this was probably not necessary. It is beneficial to the program to appear comprehensive, but the financial connotations surrounding building a program are tremendous and must be addressed before investing in equipment and inventory. If inventory is purchased and not used prior to the expiry date, the practice will incur a significant loss. Inventory can be purchased on an as needed basis, but this will be more expensive. We recommend multiple discussions with institutional leadership and financial officers', negotiation with industry and starting with IGB placement and ESG.

Obtaining the necessary training to competently perform a procedure is relatively simple. Placement of the Aspiration therapy device is similar to placing a percutaneous gastrostomy tube, and is proctored by industry training personnel. Insertion and removal of IGBs, and intra-gastric Botox can be learned in a single session. However, there is a learning curve for proficiency in ESC for length of procedure and number of plications per procedure [17]. Progress plateaus at seven to nine cases, in endoscopists with previous suturing experience for other procedures [17]. However, previous experience with endoscopic suturing is not necessary. ESG can be learned through industry led training sessions, society and academic center training courses. Currently, the first ESG will be proctored by an expert, however the gastroenterological and surgical societies are jointly creating guidance for education, training and assessment of competence. Similar to bariatric surgery it is important to have a well-trained and cohesive team, thus gastrointestinal and surgical societies provide instruction and education for nurses and technicians.

EBT can be used as a bridge to bariatric surgery in morbidly obese patients, where the risk of surgical and anesthesia related complications would otherwise be too high to make them ideal candidates. This would be an off-label use of the device for a patient that did not qualify for the procedure based on BMI requirements. Likewise, transplant and orthopedic surgeons of-

- Table 4 Weight and BMI change after endoscopic sleeve gastroplasty (ESG)

\begin{tabular}{|c|c|c|c|c|c|c|}
\hline & $\begin{array}{l}\text { Pre-procedure } \\
(\mathrm{N}=108)\end{array}$ & $\begin{array}{l}1 \text { month } \\
(n=97 / 108)\end{array}$ & $\begin{array}{l}3 \text { months } \\
(n=73 / 103)\end{array}$ & $\begin{array}{l}6 \text { months } \\
(n=61 / 91)\end{array}$ & $\begin{array}{l}12 \text { months } \\
(n=43 / 69)\end{array}$ & $P$ value $^{1}$ \\
\hline Weight, kg & $113.77(28.66)$ & $103.86(21.71)$ & $101.30(26.57)$ & $99.01(25.35)$ & $94.39(22.47)$ & $<0.001$ \\
\hline $\mathrm{BMI}, \mathrm{kg} / \mathrm{m}^{2}$ & $40.40(7.88)$ & $36.97(7.94)$ & $35.22(7.98)$ & $34.32(7.55)$ & $32.86(6.21)$ & $<0.001$ \\
\hline Absolute Weight loss, kg & & $10.64(3.97)$ & $16.31(6.14)$ & $21.33(10.09)$ & $24.43(11.49)$ & $<0.001$ \\
\hline Percent total body weight loss, \% & & $9.31(2.98)$ & $14.05(4.52)$ & $17.80(6.48)$ & $20.59(8.33)$ & $<0.001$ \\
\hline
\end{tabular}


- Table 5 Weight and BMI change at baseline, 1,3, 6, and 12 months post Orbera intra-gastric balloon (IGB) placement.

\begin{tabular}{|c|c|c|c|c|c|c|c|}
\hline & $\begin{array}{l}\text { Baseline } \\
(n=34 / 34)\end{array}$ & $\begin{array}{l}1 \text { month } \\
(n=29 / 34)\end{array}$ & $\begin{array}{l}3 \text { months } \\
(n=21 / 34)\end{array}$ & $\begin{array}{l}6 \text { months } \\
(n=29 / 34)\end{array}$ & $\begin{array}{l}9 \text { months } \\
(n=6 / 34)\end{array}$ & $\begin{array}{l}12 \text { months } \\
(n=14 / 34)\end{array}$ & $P$ value $^{1}$ \\
\hline Weight, kg & $93.86(23.21)$ & $87.72(21.69)$ & $85.75(25.10)$ & $81.46(23.14)$ & $77.99(6.87)$ & $83.22(12.54)$ & $<0.001$ \\
\hline BMI, kg/m² & $34.17(7.01)$ & $32.69(7.66)$ & $31.97(8.95)$ & $30.34(8.11)$ & $28.41(2.71)$ & $31.10(4.59)$ & $<0.001$ \\
\hline $\begin{array}{l}\text { Percent total body } \\
\text { weight loss, \% }\end{array}$ & & $7.72(6.95)$ & $11.84(8.00)$ & $14.94(9.84)$ & $12.91(8.93)$ & $10.40(6.67)$ & $<0.001$ \\
\hline $\begin{array}{l}\text { Absolute weight } \\
\text { loss, kg }\end{array}$ & & $7.85(9.33)$ & $11.91(10.82)$ & $14.39(11.48)$ & $12.26(9.71)$ & 9.59 (6.39) & $<0.001$ \\
\hline $\begin{array}{l}\text { Percent excess } \\
\text { weight loss, } \%\end{array}$ & & $42.23(63.12)$ & $47.26(22.62)$ & $60.98(36.88)$ & $60.12(34.89)$ & $44.84(35.01)$ & $<0.001$ \\
\hline $\begin{array}{l}\text { Absolute BMI re- } \\
\text { duction, } \mathrm{kg} / \mathrm{m}^{2}\end{array}$ & & $3.04(4.06)$ & $4.59(4.86)$ & $5.43(4.90)$ & $4.43(3.46)$ & 3.47 (2.39) & $<0.001$ \\
\hline
\end{tabular}

- Table 6 Weight change and BMI at baseline, 1,3,6, and 12 months post Reshape intra-gastric balloon (IGB) placement.

\begin{tabular}{|c|c|c|c|c|c|c|}
\hline & $\begin{array}{l}\text { Baseline } \\
(n=33)\end{array}$ & $\begin{array}{l}1 \text { month } \\
(n=26 / 33)\end{array}$ & $\begin{array}{l}3 \text { months } \\
(n=20 / 33)\end{array}$ & $\begin{array}{l}6 \text { months } \\
(n=29 / 30)\end{array}$ & $\begin{array}{l}12 \text { months } \\
(n=8 / 24)\end{array}$ & $P$ value $^{1}$ \\
\hline Weight, kg & $100.56(20.31)$ & $93.95(20.91)$ & $90.82(19.79)$ & $86.27(18.55)$ & $75.74(8.48)$ & $<0.001$ \\
\hline BMI, $\mathbf{k g} / \mathrm{m}^{2}$ & & $34.16(5.45)$ & $32.78(5.52)$ & $31.36(4.93)$ & $28.20(2.77)$ & $<0.001$ \\
\hline $\begin{array}{l}\text { Percent body weight } \\
\text { loss, } \%\end{array}$ & & $6.64(2.37)$ & $11.96(3.56)$ & $12.64(7.43)$ & $16.85(5.52)$ & $<0.001$ \\
\hline Absolute weight loss, kg & & $6.53(2.35)$ & $12.40(4.72)$ & $12.13(7.31)$ & $15.48(5.88)$ & $<0.001$ \\
\hline $\begin{array}{l}\text { Percent excess weight } \\
\text { loss, \% }\end{array}$ & & $24.21(12.38)$ & $41.43(16.17)$ & $46.22(29.61)$ & $67.34(25.87)$ & $<0.001$ \\
\hline $\begin{array}{l}\text { Absolute BMI reduction, } \\
\mathrm{kg} / \mathrm{m}^{2}\end{array}$ & & $2.39(0.80)$ & $4.45(1.50)$ & $4.51(2.71)$ & $5.71(1.99)$ & $<0.001$ \\
\hline
\end{tabular}

ten solicit aid with weight loss prior to major surgery to decrease risk and improve outcomes. This poses an ethical conundrum for providers. Should we offer a procedure to a less than ideal patient, knowing that they will undoubtedly benefit in the long term, or should we follow strict guidelines and be selective when choosing potential patients? The provider must recognize that the retribution for a complication or adverse outcome resulting from an elective cash pay procedure could be catastrophic. Endoscopists must comprehend the benefit and risks and communicate it explicitly to the client.

Applying for institutional review board (IRB) approval prior to launching the program will not only delay initiation, it may also create multiple hurdles along the way. Bariatric surgical centers accredited through the metabolic and bariatric surgery accreditation and quality improvement program (MBSAQIP) are required to maintain and report all data into their registry. Interestingly, Aspiration therapy and IGB which are both FDA-approved do not require an IRB. ESG on the other hand requires an IRB or an IRB exemption in an American society of metabolic and bariatric surgery (ASMBS) accredited center or center of excellence.

The most critical component of establishing an EBT program is the financial ramifications, as EBT is not reimbursed by insurance. Insertion and removal of the IGB can be performed at an ASC if the patient has a BMI less than $50 \mathrm{~kg} / \mathrm{m}^{2}$ and minimal comorbidities. For patients with a higher BMI or a precarious airway, cost must be negotiated at a hospital-based endoscopy unit. Balloon insertions can be performed with monitored anesthesia care; however, removal of fluid filled balloons should be performed with GA. One of the barriers we encountered early on was inability to negotiate ASC operative room (OR) time to perform IGB removals and ESG. There was only one OR with a GA machine which was not readily available, due to high demand from other surgical specialties. In addition, the 2-hour recovery time could potentially cause overcrowding in the postanesthesia care unit, which contained only five beds. Thus, it is advantageous to have two locations at which procedures are performed. Patients can present at any time for an emergent 
IGB removal secondary to intolerance or an adverse event. It is thus crucial that two endoscopists are trained and competent with removals.

- Table 3 depicts the cost of procedures offered at our program when performed at the hospital versus an ASC. This poses several challenges for the program. How does an academic center collect payment and how is it distributed between the hospital, division, endoscopist and anesthesia team? For example, at our program, an ESG costs \$12,265 when performed at a low-acuity endoscopy suite within a hospital. The facility collects $\$ 8,300$, anesthesia department $\$ 1,215$ and the gastroenterology division $\$ 2,750$. The most expensive part of the procedure is the OR time that is billed per minute and negotiable in most States, but not Maryland. The caveat though, is that as the endoscopist becomes more proficient, the time taken per procedure will decrease and this will drive the cost down. One must be prepared to re-negotiate so that the cost becomes more affordable as the program moves forward.

Billing and coding can be problematic and one must be prepared for unforeseen issues arising from the lack of terminology for new procedures. There is no ICD10 code for IGBs, Aspiration therapy, or ESG. A dummy code was created for the nocost consultation and each intervention so that endoscopists get adequate wRVUs for the time and effort spent. In our program, these numbers were negotiated based on procedure time, level of expertise and required training. The endoscopist receives 4 wRVUs for IGB placement and 4 wRVUs for IGB removal, and a total of 19 wRVUs for the ESG. The patient contract should make it clear that hospital admission, repeat procedures or surgical intervention if a complication occurs are not covered, and will be billed to their primary insurance. We shared written information regarding the procedure, pre and post procedure instructions, consent and contract 2 weeks prior to the scheduled procedure. All documents are signed before the procedure, so that the patient is truly well informed, the provider and institution are protected and future ramifications regarding expectations and refunds can be avoided. The financial and coding team must be educated as accidental submission and rejection by an insurance company can culminate in an unpleasant situation and a dissatisfied patient.

High-volume community practices and academic centers will have the opportunity to be a part of clinical trials and thus patients may qualify for a procedure even if they cannot afford it. In addition, we offered employees within our health system a discount. This encouraged buy-in to our practice as well as promotion through 'word of mouth'. The vast majority inquire about a flexible payment plan, but due to hospital policy, we are unable to offer this to patients. If one is able to establish a flexible payment plan it makes the program more accessible to a larger portion of the community.

It is essential to track data for patients at the EBT program. In addition, markers of quality assurance for every component of the program including dietician, behavioral psychologist and exercise physiologist should be in place. This allows one to monitor the success of all components of the program. One should consider joining a registry such as an endoscopic sutur- ing registry or EBT registry to track outcomes, adverse events and compare data.

Marketing can be arduous and expensive, but is pivotal to the success of the program. The team will need to be cleverly intuitive and inventive to prevent a perception that one is marketing to the wealthy or higher socioeconomic strata. We had little success with take one cards, education of primary care physicians and local radio shows, but interestingly patients found us through social media platforms, hospital flat screen advertising and internet search optimization. A website that is informative, yet captivating is paramount. If you are able to provide patients with a three-dimensional experience of your clinic and their proposed weight loss journey, the subsequent visit and follow up will be effortless. Do not underestimate the power of professional YouTube videos describing each procedure and descriptive patient stories that patients can relate to on your website.

We inaugurated our endobariatric program at two clinical sites with a single bariatric endoscopist and a nurse practitioner. Over 3 years we have expanded our program to four clinical sites and now have a team comprising two bariatric endoscopists, obesity medicine specialist, nurse practitioner, program coordinator, scheduler and two research assistants. The program is profitable which allows for marketing and further expansion.

\section{Conclusion}

Obesity is now a worldwide epidemic and obesity-associated disease an economic burden. An EBT program offers patients that have failed diet, lifestyle modifications and pharmacotherapy or do not qualify for bariatric surgery, an alternative for weight loss. A comprehensive EBT program can be established relatively quickly with a passionate physician leader.

\section{Competing interests}

Dr. Kumbhari is a consultant for Reshape Lifesciences, Medtronic, Boston Scientific, Pentax Medical, and Apollo Endosurgery and receives research support from Apollo Endosurgery and ERBE USA.

\section{References}

[1] Afshin A, Forouzanfar MH, Reitsma MB et al. Health effects of overweight and obesity in 195 countries over 25 years. N Engl J Med 2017; 377: $13-27$

[2] Centrals for Disease Control and Prevention. adults obesity facts. 2020: www.cdc.gov/obesity/data/adult.html (Accessed 2020 May 5)

[3] Hales CM, Carroll MD, Fryar CD et al. Prevalence of Obesity Among Adults and Youth: United States, 2015-2016. NCHS Data Brief 2017; 288: $1-8$

[4] Acosta A, Streett S, Kroh MD et al. White Paper AGA: POWER - Practice Guide on Obesity and Weight Management, Education, and Resources. Clinical gastroenterology and hepatology 2017; 15: 631-649

[5] NHLBI, NIDDK. Clinical guidelines on the identification, evaluation, and treatment of overweight and obesity in adults: the evidence report. Bethesda: National Heart, Lung, and Blood Institute; 1998 
[6] Cheskin L], Hill C, Adam A et al. Endoscopic sleeve gastroplasty versus high-intensity diet and lifestyle therapy: a case-matched study. Gastrointest Endosc 2020; 91: 342-349

[7] Courcoulas A, Dayyeh BA, Eaton L et al. Intragastric balloon as an adjunct to lifestyle intervention: a randomized controlled trial. International journal of obesity 2017; 41: 427-433

[8] Abu Dayyeh BK, Kumar N, Edmundowicz SA et al. ASGE Bariatric Endoscopy Task Force systematic review and meta-analysis assessing the ASGE PIVI thresholds for adopting endoscopic bariatric therapies. Gastrointest Endosc 2015; 82: 425-438

[9] Hedjoudje A, Dayyeh BA, Cheskin LJ et al. Efficacy and safety of endoscopic sleeve gastroplasty: a systematic review and meta-analysis. Clin Gastroenterol Hepatol 2020; 18: 1043-1053

[10] Thompson CC, Dayyeh BK, Kushnir V et al. Aspiration therapy for the treatment of obesity: 4-year results of a multicenter randomized controlled trial. Surg Obes Relat Dis 2019; 15: 1348-1354

[11] Fayad L, Adam A, Schweitzer M et al. Endoscopic sleeve gastroplasty versus laparoscopic sleeve gastrectomy: a case-matched study. Gastrointest Endosc 2019; 89: 782-788

[12] [Anonymous] Digestive Weight Loss Center. Concierge Endoscopic Weight Loss Program
[13] Fung M, Wharton S, Macpherson A et al. Receptivity to bariatric surgery in qualified patients. J Obes 2016; 2016: 5372190

[14] Conaty EA, Bonamici NJ, Gitelis ME et al. Efficacy of a required preoperative weight loss program for patients undergoing bariatric surgery. J Gastrointest Surg 2016; 20: 667-673

[15] Keith JrC], Goss LE, Blackledge CD et al. Insurance-mandated preoperative diet and outcomes after bariatric surgery. Surg Obes Relat Dis 2018; 14: 631-636

[16] Yumuk V, Tsigos C, Fried M et al. European guidelines for obesity management in adults. Obesity Facts 2015; 8: 402-424

[17] Hill C, El Zein M, Agnihotri A et al. Endoscopic sleeve gastroplasty: the learning curve. Endosc Int Open 2017; 5: E900-E904

[18] Sartoretto A, Sui Z, Hill C et al. Endoscopic sleeve gastroplasty (ESG) is a reproducible and effective endoscopic bariatric therapy suitable for widespread clinical adoption: a large, international multicenter study. Obesity Surgery 2018; 28: 1812-1821

[19] Murino A, Arvanitakis M, Le Moine O et al. Effectiveness of endoscopic management using selfexpandable metal stents in a large cohort of patients with post-bariatric leaks. Obesity Surgery 2015; 25: 15691576

[20] [Anonymous] American Board of Obesity Medicine. https://www. abom.org/ 